\title{
Essential Oil Composition of Asteriscus maritimus (L.) Less. from Spain**
}

Keywords: Asterisc us ma nitimus; Compositae, Essential Oil, Sea sona Variation, a-Pinene, P-Cymene, a-Phellandrene, B-Phellandrene, Fonenol

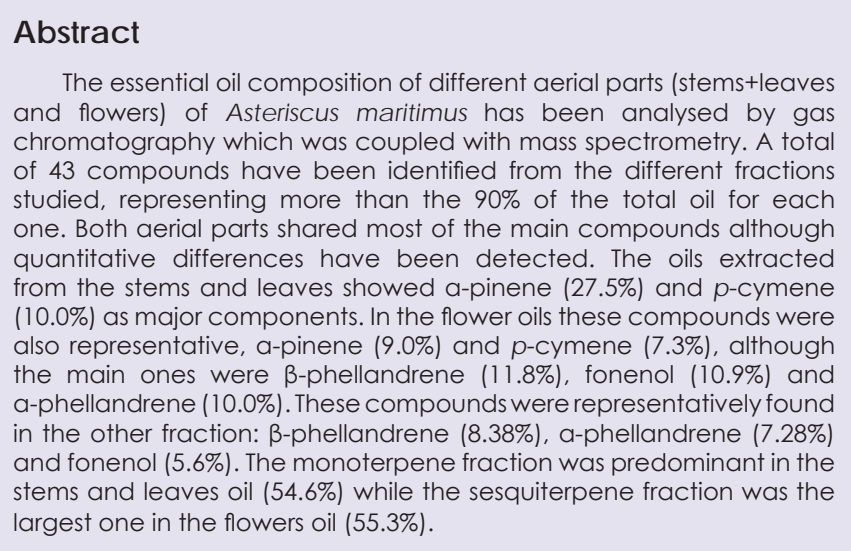

\section{Introduction}

The genus Asteriscus Miller belongs to the Compositae family. This genus and the other two of the same tribe (Ighermia Wiklund and Pallenis Cass.) contain a total of 15 species that grow wildly in a variety of coastal and desert habitats throughout the Mediterranean and Middle East [1,2]. Although most of the species are endemic of the Macaronesian region, in Europe there are two species described: A. aquaticus (L.) Less and A. maritimus (L.) Less. [3]. A. maritumus (=Odontospermum maritimum (L.) Sch.Bip.=Bubonium maritimum (L.) Hill) is a scabird, hispid perennial species with stems rarely having more than $20 \mathrm{~cm}$, woody and much-branched, with petiolate leaves from oblong to oblong-spatulate. The outer involucral bracts are around $1 \mathrm{~cm}$, coriaceous below, with an obtuse apex, equalling or shorter than ligules. The ligules are deeply 3 -toothed and the tubular florets 5-lobed [3,4].

Although Asteriscus is not a very large genus, few studies have been published related to it [5-18]. The study of the molecular systematic of some Macaronesian species exposed that Asteriscus is paraphyletic [5]. On the other hand, extracts of organic solvents from A. imbricatus DC. showed antifungal activity and anticorrosion inhibition [6]. However, most of the studies have been focused only on one species, A. graveolens (Forssk.) Less., describing their flavonoids [7], new derivatives [8,9] and essential oil activities [10-12]. The essential oil of this species was characterized by a high content of 6-oxocyclonerolidol (66.7\%) and 6-hydroxycyclonerolidol (8.8\%) which exhibited fungicidal properties towards Alternaria sp. [10]. Other report suggests that these compounds could be considered as chemical markers of this genus that characterize the stem and leaf oil, while cis-8-acetoxychrysanthenyl acetate, which has been isolated

\section{Journal of Plant Biology \& Soil Health}

Jesús Palá-Paúl ${ }^{1 *}$, Jaime Usano-Alemany ${ }^{2}$, Ana Cristina Soria ${ }^{3}$

${ }^{1}$ Dpto. Biología Vegetal I (Botánica), Facultad de Biología, Universidad Complutense de Madrid, 28040-Madrid, Spain.

${ }^{2}$ Institute of Crop Sciences and Resources Conservation. INRESHorticultural Sciences. University of Bonn, 53121-Bonn, Germany ${ }^{3}$ Instituto de Química Orgánica General (CSIC), Juan de la Cierva, 328006 Madrid, Spain

Address for Correspondence

Dr. Jesús Palá-Paúl, Dpto. Biología Vegetal I (Botánica), Facultad de Biología, Universidad Complutense de Madrid, 28040-Madrid, Spain, Tel: +00-34-91-394-50-57; E-mail: Quibey@bio.ucm.es

Submission: 29 November 2013

Accepted: 18 January 2014

Published: 23 January 2014

for the first time, was the major compound of the flower oil [11]. The last paper related to this species agreed with the previous ones, being 6-oxocyclonerolidol (74.9\%) and 6-hydroxycyclonerolidol (11.8\%) as the major components. Besides, the essential oil exhibited inhibition of mild steel corrosion [12]. We could have only found other report about essential oil composition [13]. The oils extracted from Pallenis spinosa (L.) Cass (=A. spinosus (L.) Chultz Bip) showed germacra-1(10),5-dien-3,4-diol (18.4\%), a-cadinol (14.1\%), 3-acetoxygermacra1 (10),5-dien-4-ol (13.0\%), t-cadinol (8.2\%) and $\delta$-cadinene (5.8\%) as main constituents [13].

Asteriscus maritimus has also been studied during the previous years from different point of view. Under water and saline stress conditions, this species showed lower biomass, an early reduction in leaf expansion growth and a substantial degree of stomatal regulation [14]. Recently, biological studies have shown that the diversity of arbuscular mycorrhizal fungi in this species improves salt tolerance by increasing efficiency of photosystem II, stomatal conductance and glutathione content and by reducing oxidative damage [15,16]. Finally, two previous studies have shown that the insecticidal, antimicrobial and anti-acetylcholinesterase activities were revealed by the essential oils $[17,18]$. The essential oil of aerial parts of A. maritumus from Italy showed insecticidal activity. Fourteen compounds were identified out of which one myrtenyl acetate (44.2\%), terphenyl (17.5\%) and (Z)- $\beta$-farnesene (12.9\%) were the principal ones [17]. The root oil of Asteriscus maritimus growing in Tunisia yielded Sixty six compounds which represented $96.7 \%$ of the total oil, characterized by a high proportion of oxygenated compounds (65.0\%). The root oil exhibited antifungal activity against Aspergillus flavus, A. niger, Botrytis cinerea and Penicillium sp [18].

The aim of this paper is to contribute the knowledge of the chemical composition of Asteriscus maritimus species along with the chemical compositions of its different aerial parts and comparing our results with those previously reported.

\section{Materials and Methods}

\section{Plant material}

Aerial parts of Asteriscus maritimus were collected from The 
Regional Park of Calblanque, Murcia (Spain) in 19-III-2005. All the materials belonged to the same population and around 15-20 specimens were collected. A voucher specimen (MACB-94543) has been lodged at the Herbarium of the Faculty of Biology, Complutense University, Madrid, Spain.

\section{Isolation of volatile oil}

The oils from the different aerial parts of A. maritimus were air dried and were isolated by steam distillation with cohobation for $8 \mathrm{~h}$. according to the method recommended in the Spanish Pharmacopoeia. The oils were dried over anhydrous magnesium sulphate and stored at $4^{\circ} \mathrm{C}$ in the dark. The different distilled fractions yielded a very low amount of pale yellow oil, being $0.17 \%$ and $0.42 \%$ from stems+leaves and flowers respectively, based on dry weight.

\section{Gas Chromatography (GC)}

The analytical gas chromatography (GC) was carried out on a Varian 3300 gas chromatograph fitted with a fused methyl silicone DB-1 column ( $50 \mathrm{~m} \mathrm{x} 0.25 \mathrm{~mm}, 0.25 \mu \mathrm{m}$ film thickness). Temperature was programmed from $95^{\circ} \mathrm{C}-240^{\circ} \mathrm{C}$ at $4^{\circ} \mathrm{C} \mathrm{min}^{-1}$. Injection was performed at $250^{\circ} \mathrm{C}$ in the split mode (1:100). Nitrogen was used as the carrier gas $\left(1.5 \mathrm{~mL} \mathrm{~min}^{-1}\right)$. Detection was performed by FID at $300^{\circ} \mathrm{C}$. Injection volume for all the samples was $0.1 \mu \mathrm{L}$ of pure oil.

\section{Gas Chromatography-Mass Spectrometry (GC-MS)}

GC-MS analyses were carried out on an Agilent Technologies 6890 gas chromatograph coupled a Hewlett-Packard 5973 quadrupole mass detector. Injections were carried out in split mode (20:1) at $250^{\circ} \mathrm{C}$. Separations were performed using two columns with different stationary phase (i) a SE-30 capillary column $(50 \mathrm{~m} \mathrm{x} 0.22 \mathrm{~mm}, 0.25$ $\mathrm{mm}$ film thickness) temperature programmed from $70^{\circ} \mathrm{C}$ to $220^{\circ} \mathrm{C}$ at $4^{\circ} \mathrm{C}$ min-1, and (ii) a DB-Wax column $(60 \mathrm{~m} \mathrm{x} 0.32 \mathrm{~mm}, 0.25 \mathrm{~mm})$ programmed from $70^{\circ} \mathrm{C}$ to $220^{\circ} \mathrm{C}$ at $3^{\circ} \mathrm{C}$ min- 1 . Helium at $1 \mathrm{~mL} \mathrm{~min}$ ${ }^{1}$ was used as carrier gas. Mass spectra were recorded in electronic impact (EI) mode at $70 \mathrm{eV}$, scanning the $35-350 \mathrm{~m} / \mathrm{z}$ range. Interface and source temperature were $280^{\circ} \mathrm{C}$ and $230^{\circ} \mathrm{C}$, respectively. All analyses were performed in duplicate.

\section{Qualitative and quantitative analyses}

Most constituents were tentatively identified by GC by comparison of their retention indices with those of authentic standards available in the author's laboratory or with retention indices from references [19-23]. Further identification was achieved by GC-MS: the fragmentation patterns of the mass spectra were compared with those stored in the spectrometer data base using the WILEY.L built-in library. Other constituents were either synthesised or identified in oils of known composition. Semiquantitative analysis was carried out directly from peak areas in the GC profile.

\section{Results and Discussion}

According to our results and previously reported ones, Asteriscus does not produce high quantity of essential oils. While $P$. spinosa showed the lowest yield $(0.04 \%)$ [13], the other species of the genus studied till date had similar results: A. graveolens showed an yield (0.06\%) [12] and A. maritimus from Italy showed the yield of $0.06 \%$ [17]. It is worth noting that for P. spinosa and A. maritimus, the yields were calculated on fresh weight. In our study, the oil amount was little bit higher for both studied fractions: $0.17 \%$ for stems+leaves oil and $0.42 \%$ for flowers. The yield was based on dry weight that could explain the differences between our results and those above mentioned. Besides, as far as we know it is the first time that the aerial parts of this plant are distilled separately. The flowers contained more oil than the stems and leaves. The oil increase during the flowering period could attract the pollinators of this species to facilitate its cross fecundation, as we have previously published for a relative species, Santolonia rosmarinifolia L. ssp. rosmarinifolia [24]. However, more research should be carried out on this species and other of the same genus to check whether the different fractions of the plant have different yields.

The components identified from the different aerial parts of Asteriscus maritimus, their retention indices and their percentage composition are summarised in Table 1 where all the compounds are arranged in order of their elution on the DB-1 column. A total of 43 compounds have been identified from the different fractions studied, representing more than the $90 \%$ of the total oil for each one. We have found qualitative differences between the studied fractions although both of them share practically all their principal and representative constituents. The oil from the stems and leaves showed $\alpha$-pinene $(27.5 \%)$ and $p$-cymene $(10.0 \%)$ as major components, while from oil from the flower fractions showed $\alpha$-pinene $(9.0 \%)$ and $p$-cymene (7.3\%), but out of which the main ones were $\beta$-phellandrene (11.8\%), fonenol (10.9\%) and $\alpha$-phellandrene (10.0\%). These compounds were represented in the other fraction although their percentage compositions were lower than 10\%: $\beta$-phellandrene (8.3\%), $\alpha$-phellandrene (7.2\%) and fonenol (5.6\%).

With respect to the terpenoid compounds we have also found differences between the analysed parts (Table 1). While the monoterpene fraction was predominant in the stems and leaves oil $(54.6 \%)$, the sesquiterpene fraction was higher in the flowers oil (54.9\%). However, in both of them the monoterpene hydrocarbons were more abundant $53.7 \%$ (A.m.SL) and 38.6\% (A.m.Fl) than the oxygenated monoterpenes. Contrary in the sesquiterpene fraction which the oxygenated compounds showed higher percentage composition $29.3 \%$ (A.m.SL) and 34.9\%.

Previous reports suggest that the compounds 6-oxocyclonerolidol and 6-hydroxycyclonerolidol "could be considered as chemical markers of this genus" [11]. We disagree with this affirmation. These compounds have been already mentioned in only one of the studied species, A. graveolens [10-12]. An exhaustive studies are necessary to check that affirmation, although may be they could be significant for the cited species.

Finally, remarkable differences have been found between our results and those previously published [17]. The oil analysed by us seemed to be more complex with a total of 43 compounds identified in comparison with the 14 constituents cited. Besides, it is worth nothing that not only the main compounds were different in both studies, compounds as myrtenyl acetate (44.2\%), terphenyl (17.5\%) and $(Z)$ - $\beta$-farnesene $(12.9 \%)$, could not be detected by us although were reported as main ones. In fact, we only detected, in low amounts, 4 of the 14 constituents were described. These differences could be caused by the develop state of the samples or because of chemotypes existence. A phenological study of both populations should be done to 
Citation: Palá-Paúl J, Usano-Alemany J, Soria AC. Essential Oil Composition of Asteriscus maritimus (L.) Less. from Spain ${ }^{* *}$. J Plant Biol Soil Health. 2014;1(2): 4

Table 1: Essential Oil composition of the aerial parts of A. maritimus from Spain.

\begin{tabular}{|c|c|c|c|}
\hline Compound & 1 & A.m.SL & A.m.FI \\
\hline$\alpha$-pinene & 934 & 27,5 & 9,0 \\
\hline sabinene & 982 & 0,3 & 0,1 \\
\hline myrcene & 991 & 0,4 & 0,4 \\
\hline$\alpha$-phellandrene & 1005 & 7,2 & 10,0 \\
\hline$p$-cymene & 1019 & 10,0 & 7,3 \\
\hline$\beta$-phellandrene & 1027 & 8,3 & 11,8 \\
\hline cis-sabinene hydrate & 1060 & $t$ & $t$ \\
\hline terpinen-4-ol & 1170 & $\mathrm{t}$ & $\mathrm{t}$ \\
\hline a-terpienol & 1180 & $\mathrm{t}$ & $\mathrm{t}$ \\
\hline thymol methyl ether & 1230 & 0,2 & 0,2 \\
\hline bornyl acetate & 1280 & 0,6 & $\mathrm{t}$ \\
\hline trans-verbenyl acetate & 1290 & $t$ & 0,1 \\
\hline iso-verbenol acetate & 1305 & $\mathrm{t}$ & 0,2 \\
\hline$\delta$-elemene & 1330 & $\mathrm{t}$ & $\mathrm{t}$ \\
\hline$\alpha$-ylangene & 1365 & $\mathrm{t}$ & $\mathrm{t}$ \\
\hline$\beta$-cubebene & 1390 & 0,1 & $\mathrm{t}$ \\
\hline$\alpha$-cedrene & 1407 & 0,1 & 0,2 \\
\hline E-caryophyllene & 1414 & $t$ & 1,0 \\
\hline$\beta$-gurjunene & 1430 & 0,8 & 0,7 \\
\hline y-elemene & 1431 & $t$ & $\mathrm{t}$ \\
\hline cis-muurola-4(14),5-diene & 1462 & 0,5 & 1,2 \\
\hline allo-aromadendrene & 1465 & 1,6 & 3,1 \\
\hline a-selinene & 1480 & 0,5 & $\mathrm{t}$ \\
\hline epi-cubebol & 1487 & 1,3 & 2,0 \\
\hline bicyclogermacrene & 1496 & 1,1 & 3,7 \\
\hline sesquicineole & 1507 & 3,0 & 6,3 \\
\hline cubebol & 1510 & $t$ & $\mathrm{t}$ \\
\hline$\delta$-cadinene & 1518 & 3,5 & 9,1 \\
\hline cadina-1,4-diene & 1532 & 0,5 & 1,0 \\
\hline a-cadinene & 1545 & $\mathrm{t}$ & $\mathrm{t}$ \\
\hline 1-nor-bourbonene & 1551 & 4,9 & 0,1 \\
\hline globulol & 1582 & $\mathrm{t}$ & 0,2 \\
\hline viridiflorol & 1592 & 0,1 & 0,2 \\
\hline E-dehydro-apofarnesol & 1595 & $t$ & $\mathrm{t}$ \\
\hline 1-epi-cubenol & 1623 & 0,1 & 0,1 \\
\hline fonenol ${ }^{*}$ & 1630 & 5,6 & 10,9 \\
\hline epi-a-muurolol + epi-a-cadinol & 1642 & 1,9 & 5,7 \\
\hline a-muurolol & 1647 & 0,5 & $\mathrm{t}$ \\
\hline a-cadinol & 1652 & $\mathrm{t}$ & 6,8 \\
\hline epi-a-bisabolol & 1690 & 0,7 & $\mathrm{t}$ \\
\hline cis-14-muurolol-5-en-4-one & 1694 & $\mathrm{t}$ & $\mathrm{t}$ \\
\hline$(E, Z)$-farnesol + 6S,7R-bisabolene $(84,100)^{*}$ & 1738 & 3,5 & $\mathrm{t}$ \\
\hline n.i. 1 & 1839 & 0,7 & $\mathrm{t}$ \\
\hline n.i. 2 & 1857 & 0,3 & $\mathrm{t}$ \\
\hline n.i. 3 & 1891 & $t$ & 0,4 \\
\hline $\begin{array}{l}\text { bis (2methylpropenyl) ester } \\
\text { 1,2-benzenedicarboxylix acid* }\end{array}$ & 1894 & 0,3 & 0,2 \\
\hline n.i. 4 & 1975 & 6,4 & 1,9 \\
\hline n.i. 5 & 1982 & $t$ & 0,2 \\
\hline \multicolumn{2}{|l|}{ Monoterpene hydrocarbons } & 53.7 & 38.6 \\
\hline \multicolumn{2}{|l|}{ Oxygenated monoterpenes } & 0.9 & 0.5 \\
\hline \multicolumn{2}{|l|}{ Sesquiterpene hydrocarbons } & 8.8 & 20.0 \\
\hline \multicolumn{2}{|l|}{ Oxygenated sesquiterpenes } & 29.3 & 34.9 \\
\hline \multicolumn{2}{|l|}{ Total } & 92.7 & 94,0 \\
\hline
\end{tabular}

$I=$ Kováts retention indices on DB- 1 column; $t=$ traces $(\%<0.1)$; $n$.i. = not identified A.m.=Asteriscus maritimus; $\mathrm{SL}=$ stems and leaves; Fl=Flowers; ${ }^{*}=$ Tentatively identified; n.i. $1 \quad l=1839220\left[\mathrm{M}^{+}\right](10), 159(100), 132(80), 91(40), 105(35)$ 177(30), 202(15); n.i. 2 I=1857 220[M+1(10), 143(100), 43(100), 93(60), 121(35), 67(25), 205(5);n.i. 3 l=1891 260[M+](3), 132(100), 159(40), 43(20), 202(15); n.i. $4 l=1975280\left[\mathrm{M}^{+}\right](5), 43(100), 81(90), 71(40), 159(35), 123(20), 177(15)$ n.i. $5 \mathrm{l}=1982278\left[\mathrm{M}^{+}\right](5), 149(100), 41(10), 76(10), 104(10), 205(10), 223(10)$, 123(10), 177(5) contrast this hypothesis. The climatic conditions of the different places where the samples were collected could not cause these differences, because A. maritmus grows in coasts of the Mediterranean where the climate conditions are very similar. May be the characteristics of the soil could cause these differences. We have previously reported the effect of the soil in the essential oil composition of Eryngium campestre L. [25], although most of the differences were quantitative but not qualitative. However, we will try to study other Spanish populations of this species to study it.

The root essential oil of this species has also been studied and they exhibited antifungal activity against Aspergillus flavus, A. niger, Botrytis cinerea and Penicillium sp and low anti-acetylcholinesterase activity [18]. This part of the plant seems to be more complex, more compounds were identified and the terpenoind fractions were also different. The root oil was characterized by high amounts of oxygenated compounds (65.0\%) while in our study $30.2 \%$ and $35.4 \%$ were registered for A.m.SL and A.m.Fl. The hydrocarbon compounds were predominant in our oils $62.5 \%$ (A.m.SL) and 58.6\% (A.m.Fl) and lower in the root oils $31.7 \%$. However, with respect to the monterpenes and sesquiterpenes the stems and leaves fraction was similar to the root one: $54.6 \%$ in comparison with $51.1 \%$ for monoterpenes and $38.1 \%$ in comparison with $45.9 \%$ for sesquiterpenes [18]. One more time the phenologycal state of this species seems to affect the chemical composition. Further researches are necessary to analysis the variability between populations and between the different parts of this species.

\section{Conclusion}

The aerial parts of $A$. maritimus yielded low amount of essential oil. Quantitative differences have been found between the A.m.SL and A.m.Fl oils. The A.m.SL oil was characterized by monoterpene compounds and the A.m.Fl oil by sesquiterpene ones. The chemical composition of the essential oil seems to be affected by the part of the plant used. The major components were found to be $\alpha$-pinene (27.5\%) and $p$-cymene (10.0\%) for of A.m.SL oil and $\beta$-phellandrene (11.8\%), fonenol (10.9\%) and $\alpha$-phellandrene (10.0\%) for A.m.Fl oil.

\section{References}

1. Anderberg AA (1994) Tribe Inuleae in: Asteraceae cladistics and classification. K. Bremer Portland, Timber Press: Oregon.

2. Peltier JP (1973) Endémiques Macaronésiennes au Maroc. Monogr. Biol. Canariensis 4: 134-142.

3. Tutin TG, Heywood VH, Burges NA, Moore DM, Valentine DH, et al. (1976) Flora Europaea. (Vol. 4), Cambridge University Press.

4. Digital version of the Flora Europaea.

5. Goertzen LR, Francisco-Ortega J, Santos-Guerra A, Mower JP, Linder CR, et al. (2002) Molecular systematics of the Asteriscus alliance (Asteraceae: Inuleae) II: Combined nuclear and chloroplast data. Syst Bot 27: 815-823.

6. Senhaji B, Ben Hmamou D, Salghi R, Zarrouk A, Chebli B, et al. (2013) Asteriscus imbricatus Extracts: Antifungal activity and anticorrosion inhibition. Int J Electrochem. Sci 8: 6033-6046.

7. Ahmed AA, Ishak MS, Micheal HN, El Ansari MA, El Sissi HI (1991) Flavonoids of Asteriscus graveolens. J Nat Products 54: 1092-1093.

8. Sarg TM, El-Dahmy SI, Ateya AM (1994) Two new bisabolone hydroperoxides and biological activity of Asteriscus graveolens. Fitoterapia 65: 241-244.

9. El-Dahmy S, Jakupovic J, Bohlmann F, Sarg TM (1985) New humulene derivatives from Asteriscus graveolens. Tetrahedron 41: 309-316. 
Citation: Palá-Paúl J, Usano-Alemany J, Soria AC. Essential Oil Composition of Asteriscus maritimus (L.) Less. from Spain ${ }^{* *}$. J Plant Biol Soil Health. 2014;1(2): 4

10. Znini M, Cristofari G, Majidi L, Mazouz H, Tomi $P$, et al. (2011) Antifungal activity of essential oil from Asteriscus graveolens against postharvest phytopathogenic fungi in apples. Nat Prod Commun 6: 1763-1768.

11. Cristofari G, Znini M, Majidi L, Mazouz H, Tomi P, Costa J, Paolini J (2012) Chemical diversity of essential oils from Asteriscus graveolens (Forssk.) Less.: Identification of cis-8-acetoxychrysanthenyl acetate as a new natural component. Chem Biodiver 9: 727-738.

12. Znini M, Cristofari G, Majidi L, Ansari A, Bouyanzer A, et al. (2012). Green approach to corrosion inhibition of mild steel by essential oil leaves of Asteriscus graveolens (Forssk.) in sulphuric acid medium. Int J Electrochem Sci 7: 3959-3981.

13. Senatore F, Bruno M (2003) Composition of the essential oil of Pallenis spinosa (L.) Cass. (Asteraceae). Flavour Frag J 18: 195-197.

14. Rodriguez $P$, Torrecillas A, Morales MA, Ortuno MF, Sanchez-Blanco M (2005) Effects of $\mathrm{NaCl}$ salinity and water stress on growth and leaf water relations of Asteriscus maritimus plants. Environmental Exp Bot 53: 113-123.

15. Estrada B, Aroca R, Azcon-Aguilar C, Barea JM, Ruiz-Lozano JM (2013) Importance of native arbuscular mycorrhizal inoculation in the halophyte Asteriscus maritimus for successful establishment and growth under saline conditions. Plant Soil 370: 175-185.

16. Estrada B, Beltran-Hermoso M, Palenzuela J, Iwase K, Ruiz-Lozano JM, et al. (2013) Diversity of arbuscular mycorrhizal fungi in the rhizosphere of Asteriscus maritimus (L.) Less., a representative plant species in arid and saline Mediterranean ecosystems. J Arid Environ 97: 170-175.
17. Fraternale D, Giamperi L, Ricci D, Manunta A (2001) Composition and insecticidal activity of the essential oil of Asteriscus maritimus (L.) Less. Rivista Italiana Eppos 11: 33-40

18. Medimagh S, Daami-Remadi M, Jabnoun-Khiareddine $H$, Naffati M, Ben Jannet $\mathrm{H}$, et al. (2013) Chemical composition and in vitro evaluation of antimicrobial and anti-acetylcholinesterase activities of the root oil from Asteriscus maritimus (L.) Less Growing in Tunisia. J Essent Oil Bear PI 16: $443-450$.

19. Adams RP (1995) Identification of essential oils components by gas chromatography/mass spectroscopy. Allured Publishing Co., Illinois.

20. Heller SR, Milne GWA (1983) EPA/NIH mass spectral data base. US Government Printing Office: Washington DC.

21. Stenhagen E, Abrahamsson S, McLafferty FW (1974) Registry of mass spectral data. (1st edtn), Wiley: New York.

22. Swigar AA, Silverstein RM (1981) Monoterpenes. Aldrich, Milwaukee.

23. Joulain D, König AW (1998) The Atlas of Spectral Data of Sesquiterpene Hydrocarbons. E. B.-Verlag Hamburg, Germany.

24. Palá-Paúl J, Pérez-Alonso MJ, Velasco-Negueruela A, Palá-Paúl R, Sanz $\mathrm{J}$, et al. (2001) Seasonal variation in chemical constituents of Santolina rosmarinifolia L. ssp. rosmarinifolia. Biochem System Ecol 29: 663-672.

25. Palá-Paúl J, Usano-Alemany J, Soria AC, Pérez-Alonso MJ, Brophy JJ (2008) Essential oil composition of Eryngium campestre L. growing in different soil types. A preliminary study. Nat Prod Commun 3: 1121-1126.

\section{Acknowledgements}

** Part of this paper has been presented as a poster at the 38th International Symposium on Essential Oils, Graz (Austria), September 9-12 2007 